\title{
Alternative financial models for attracting investments in municipal investment and construction projects
}

\author{
Oksana Kurakova ${ }^{1, *}$ \\ ${ }^{1}$ Moscow State University of Civil Engineering, Yaroslavskoye Shosse, 26, Moscow, 129337, Russia
}

\begin{abstract}
Investment and construction projects, which require colossal costs, are especially affected in the conditions of scarcity of funds. City authorities also experience an acute shortage of finances for the implementation of municipal investment and construction projects. This article presents the mechanism of applying innovative tools for investments attraction in Russia to implement investment and construction projects. These tools include Internet marketing tools. The article presents an analysis of characteristics of each tool, their advantages and disadvantages in use. This article also includes practical examples of how these tools can work for the purposes of investment and construction projects implementation, including municipal or social ones. Examples of already implemented projects based on the use of Internet marketing tools are given. The author suggests an innovative model of municipal projects financing. The analysis showed that similar technologies for municipal investment and construction projects financing are quite viable and are currently underestimated in Russia.
\end{abstract}

\section{Introduction}

Under conditions of an unstable economic situation and scarcity of financial resources pronounced in all spheres, the problem of finding and attracting investments is urgent as never before. According to Rosstat, construction of real estate in Russia in 2017 decreased by $13.2 \%$ as compared to 2016 . Even if we do not refer to any statistics and rely only on considerable changes in the economy in recent years, it is easy to conclude that the problem related to the search for investors in the area of investment and construction projects is acute. This problem is especially relevant for projects financed from municipal funds and projects that are most often social rather than commercial [1].

In this article non-standard and hardly applicable, especially in Russia, ways of attracting investments for the implementation of this type of investment projects, namely, use of Internet marketing tools are considered. An important factor is that all of the below mentioned tools and schemes for investor search are not universal and require careful analysis and competent understanding of parameters of each particular project. There are also a number of negative factors hampering the development of Internet marketing in

\footnotetext{
*Corresponding author: ks-home@mail.ru
} 
Russia, which should also be taken into account. For example, the human factor - a conservative attitude towards the implementation of projects and repudiation of the digital sphere as a whole. An important role is played by the lack of qualified specialists in the area of Internet marketing in regions, as well as a rather complicated procedure for specialists monitoring, taking into account the traditional and systematic error made when selecting KPIs (key performance indicators). But the trend towards the application of foreign innovations in our country, as well as availability of working methods, for example in Canada, allow us to conclude that the widespread use of Internet marketing tools in the area of investment and construction processes is a matter of foreseeable future [2].

\section{Materials and methods}

The first and simplest option reflecting work with behavioural factors on the Internet, which is not an Internet marketing tool, is search for thematic resources that are a permanent habitat for the target audience. In the context of investment and construction projects, these are various construction forums, online publications, exchanges, and interest clubs. Example: stroi-baza.ru, moscow.mirstroek.ru, yondi.ru and so on. If you disregard the construction theme and set the goal to find an investor in principle, then there is a large number of active websites for communication: investclub.ru, investtalk.ru, bzb.ru. It is worth noting that everything often depends on the specifics of the project, so the task of finding the target audience and working with specific communication resources is reduced to understanding of all aspects of the project by the contractor, which in turn requires the presence of such an executor in the staff of the company engaged in attracting investments. The task of a full-time specialist in Internet marketing, or, which is the most common option, an employee who performs the function of such a specialist is minimized: he or she shall be able to create a search query and select the necessary resources on the Internet. Also, a no less important factor is consideration of specifics of such resources: forum rules; the ability to influence ad ranking for an additional fee to increase the number of views and so on. It is worth highlighting business social networks as a separate category - western ones that are popular in our country, for example Linkedin.com, and national ones. Work on the attraction of investments in such social networks is possible only because of their business nature that differs from the usual entertaining nature of such resources.

It was possible to find 2,862 forms on request "investor" in social network Linkedin.com as of March 2017. All of the above in the aggregate is the most budgetary option to search for investments on the Internet and, under certain conditions, require only time from the project participant. It should be noted that in order to achieve certain results within the preset timeframe, it is necessary to approve the budget of the advertising campaign and distribute it across priority channels, taking into account the specifics and scope of the investment project [3].

For a broader overview of the possibilities of investments attraction with the help of Internet technologies, one can draw an analogy with the smoothly running and successfully functioning government procurement system available in our country. There are a number of official state websites, where interaction between private and public organizations is possible. Moreover, tender seekers are equipped with a special digital signature, and all contracts can be concluded remotely. By projecting this example on the scheme of work under consideration, it can be concluded that work using Internet tools is possible even at the highest level. There are not so many key differences in both schemes of work. If we talk about investments attraction, then it should be noted that in this case a presentation and communication activity is carried out, and the only one stakeholder is initially available. In case of government orders, a private organization needs a department or a number of employees who will be able to deal with this area. As for investments attraction, availability 
of such specialists or transfer of strategic tasks to outsource is not a necessity. There are a number of methods that are not systematized and do not require a professional Internet marketing specialist, in view of the fact that these techniques in fact, as already mentioned above, cannot be called Internet marketing elements.

According to Yandex Wordstat, the word "investor" is requested more than 157 thousand times a month. 28 thousand of these requests come from Moscow residents. Displaying advertisements in these systems directly depends on the content of the web page that the user is viewing at any given time, as well as on specific user requests. By visiting a website dedicated, for example, to buying air tickets, the user will become the target of a relevant advertising offer to buy tickets from other organizations. So, this is how the need is identified without a questionnaire survey and other marketing methods. In case of investments attraction, only the ultimate goal can change, but in general it is work on the methodology of lead management. In the classical model of attribution, ad clicks (transition) and performance of the targeted action are important Depending on the placement position and specific request, transition of one interested user will cost $7-500$ rubles. Cost per click depends directly on the degree of competition and frequency of queries.

There are a number of other tools that do not require detailed configuration, but can give results in a short time. They will cost several thousand rubles, but in certain cases, their use is a rational option. For example, banner advertising of various formats on the above forums and portals. Use of a high-quality banner on a website, on which the target audience is focused, allows to expand the scope of search and achieve results as soon as possible. Ideally, a method of mutually beneficial cooperation with one or another website for placement shall be applied $[4,5]$.

It is worth noting that not all methods of Internet marketing can successfully adapt to the sphere of attracting investments for construction projects. For example, SEO promotion (optimization of websites to raise them in search results) will not bring any results due to the need for a long and constant work in this area. It is impossible to get excellent results from SEO promotion in a short span of time, since it should not take much time to solve the issue of investments attraction as compared to promotion in search results. [6,7]

There are tools that allow displaying targeted advertising and processing of retargeting bases (display of ads to the audience that was previously collected) in social networks, even in the entertainment segment. In the first case the social network proposes to choose demographic and other parameters (interests, position, university, etc.) to display advertising to the owners of those forms that may potentially be interested in your proposal. In the second case ads are shown only to those people, who were entered into the database (for example, the form can be included into the database when visiting a particular website, if a special code is assigned to it). Of course, in the case under consideration it is logical to direct the advertising budget to work in the abovementioned business social networks, without taking into account entertainment ones.

Standard sales methods for working in social networks will not work in this case. It is irrational to waste time on the formation of a loyal community, on the development of a content-marketing direction. In some cases useful and valuable content can only help to present an investment project, but not to form a solvent audience around it.

It is also worth highlighting e-mail newsletters among multiple tools of Internet marketing. In this case it is necessary to find or collect a database of e-mails and develop a correct proposal, keeping in mind that you should secure your letter from a potential opportunity of getting the "spam" label. Modern automated e-mail delivery services have their own systems of moderation and control, so when using them the likelihood that a potential investor will consider the proposal increases by times [8]. 
The most important issue that is required when generating advertisements is creation of a so-called landing page. This is a one-page website that provides for only one targeted action (leave your phone, order a product or subscribe to e-mail newsletters). After clicking on the advertisement anywhere, a potential investor should be redirected to the landing page, where he or she can find information about all advantages of the project, details and conditions, and will have a possibility to leave his/her contact data or contact a representative of the company. Such one-page websites are the option that brings more conversions as compared, for example, to redirecting to the website of the project organization. This is due to the fact that a person, who came using the ad and is, therefore, interested in the project will see the necessary information and have a possibility to perform only one targeted action. Distribution of attention that will have place when redirecting to the organization's website will significantly reduce the conversion. It is possible to create a landing page both using experts' skills or independently. There is a huge amount of free or low-cost solutions, which will allow creating one-page websites for sending advertising traffic to it under conditions of a very restricted budget.

\section{Results}

Crowdfunding platforms or so-called systems of financing from a large number of individuals are a separate option for attracting investments. Western websites that have been successfully functioning for a long time manifested themselves well in Russia. The essence of such platforms is in the fact that the project participant publishes detailed information about what should be implemented and sets benefit frameworks for investors of different sizes. A vivid example is construction of the manor of the national school of leaders "Zhuravli" in Kostroma (Figure 1).

Another option for attracting investments is use of proven tools for the generation of traffic on the Internet. To carry out activities in this direction, a compulsory condition is to attract a highly qualified specialist to the project, as well as carry out a detailed control of the advertising budget. Today there are many different tools, but in the Russian market the most effective and, accordingly, the most used techniques are clearly expressed.

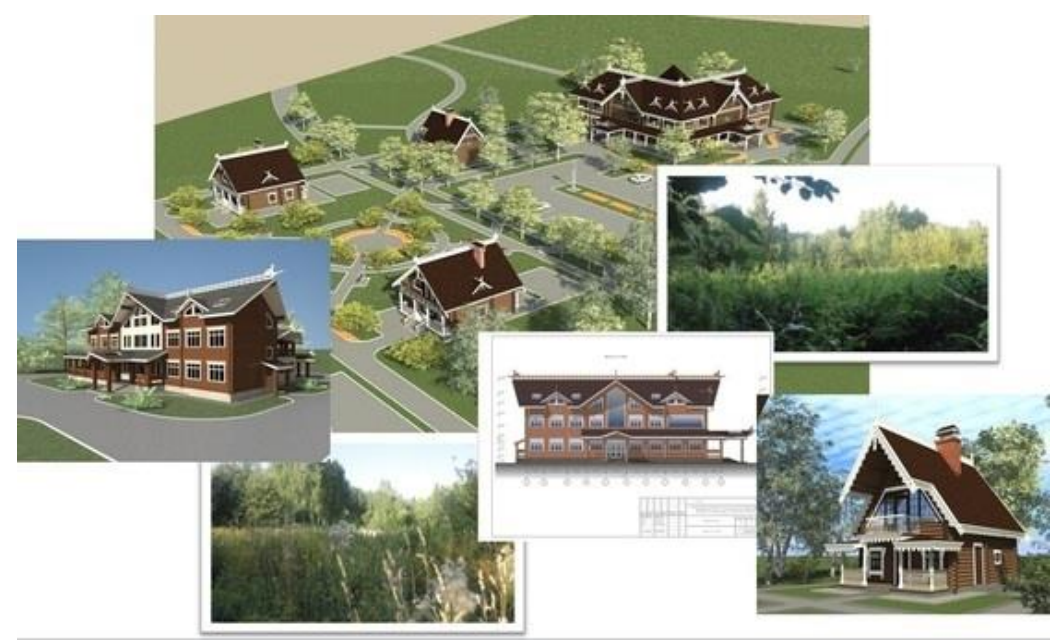

Fig. 1. Project of Zhuravli Manor in Kostroma.

The authors of the project were located on Russian crowdfunding platform boomstarter.ru and managed to collect 3,060,000 rubles. It was assumed that potential investors can invest from 400 to $1,000,000$ rubles and will get special privileges and 
benefits after project implementation. For example, an investor who invested 10,000 rubles received a link to download a package of educational materials from "Zhuravli" school, the right to participate in a training session of the institution, free travel, accommodation and meals on the territory of the manor, as well as a place in the organization's honour book. A large number of crowdfunding platforms on the RuNet and the fact that there are successfully implemented projects suggest that placement on such platforms (especially in the area of production construction, where there is a possibility to determine a direct benefit for investors) can raise funds for the implementation of an investment and construction project.

Another example is construction of a multifunctional animal care centre near Moscow (Figure 2). The project description was posted on Russian website Planeta.ru. Funds collection that was completed by 2017 allowed raising 5,050,832 rubles.

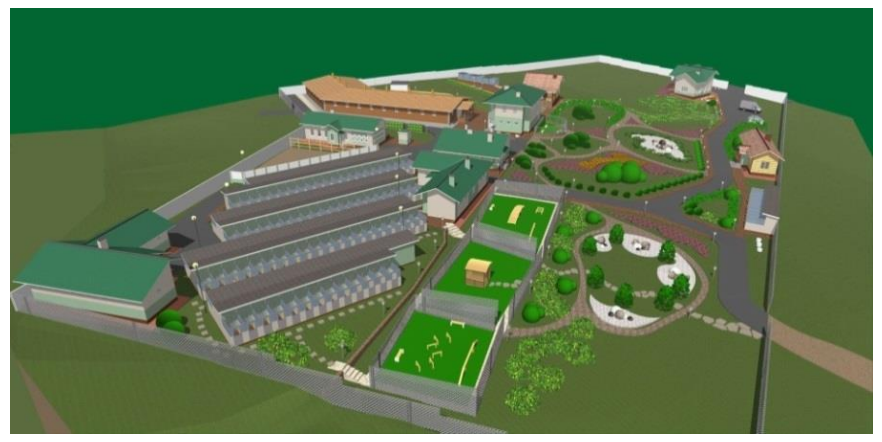

Fig. 2. The project of a multifunctional animal care centre.

\section{Conclusions}

As follows from the presented analysis of Internet marketing tools using certain examples of implementation of investment and construction projects, including social ones, city authorities should pay more attention to such innovative financial models for the development of municipal and social projects. The author suggests an innovative model of municipal projects financing. And the above examples confirmed that such technologies are quite viable for the implementation of the above goals and are currently underestimated in Russia.

\section{References}

1. S.M.R. Alavipour, D. Arditi, Journal of Construction Engineering and Management 144(4), 04018012 (2018)

2. A.K. Orlov, MATEC Web of Conferences 106, 08013 (2017)

3. D. Lucius, Journal of Property Investment and Finance 19, 73-78 (2001)

4. P. Bakhshi, A. Touran, Procedia Engineering 85, 52-60 (2014)

5. C. Tam, V. Tam, W. Tsui, International Journal of Project Management 22(7), 563$571(2004)$

6. H. Feng, K. Hewage, Energy and Buildings 75, 281-289 (2014)

7. H. Jang, S. Choi, W. Kim, C. Chang, KSCE Journal of Civil Engineering 16(7), 11151122 (2012)

8. O. Alshamrani, K. Galal, S. Alkass, Building and Environment 80, 61-70 (2014) 